\title{
Valorization of stainless steel slag by selective chromium recovery and subsequent carbonation of the matrix material
}

E. Kim $^{1,2,{ }^{*}}$, J. Spooren ${ }^{1}$, K. Broos ${ }^{1}$, P. Nielsen ${ }^{1}$, L. Horckmans ${ }^{1}$, R. Geurts ${ }^{1}$, K. C. Vrancken ${ }^{1,2}$, M. Quaghebeur ${ }^{1}$

${ }^{1}$ VITO - Flemish Institute for Technological Research, Boeretang 200, BE-2400 Mol, Belgium

${ }^{2}$ Department of Bioengineering, University of Antwerp, Groenenborgerlaan 171, BE-2020 Antwerp, Belgium

${ }^{*}$ Corresponding author

E-mail address: key7649@gmail.com, eunyoung.kim@vito.be

Address: VITO, Boeretang 200, BE-2400 Mol, Belgium

Tel: $+32-14-33-57-35$

Keywords: $\mathrm{Cr}$ (Chromium), alkaline pressure leaching, mechanical activation, carbonation, hydrometallurgy 


\title{
Valorization of stainless steel slag by selective chromium recovery and
} subsequent carbonation of the matrix material

\author{
E. Kim ${ }^{1,2,{ }^{*}}$, J. Spooren ${ }^{1}$, K. Broos ${ }^{1}$, P. Nielsen ${ }^{1}$, L. Horckmans ${ }^{1}$, R. Geurts ${ }^{1}$, K.C. Vrancken ${ }^{1,2}$, M. Quaghebeur ${ }^{1}$ \\ ${ }^{1}$ VITO - Flemish Institute for Technological Research, Boeretang 200, BE-2400 Mol, Belgium \\ ${ }^{2}$ Department of Bioengineering, University of Antwerp, Groenenborgerlaan 171, BE-2020 Antwerp, Belgium
}

\begin{abstract}
This study focuses on the recycling of stainless steel (SS) slags containing about 1.2 wt\% of chromium ( $\mathrm{Cr}$ ). The selective recovery of $\mathrm{Cr}$ from SS slag by a hydrometallurgical method (alkaline pressure leaching) was investigated. Leaching experiments were carried out based on $2^{4-1}$ factorial design of experiment (DOE) with the following parameters: $\mathrm{NaOH}$ concentration, temperature, leaching time, and mechanical activation (MA). Results show that temperature and $\mathrm{MA}$ are the most influencing factors for an enhanced $\mathrm{Cr}$ leaching. The maximum $\mathrm{Cr}$ leaching was $46 \%$ at $1 \mathrm{M} \mathrm{NaOH}, 240{ }^{\circ} \mathrm{C}, 6 \mathrm{~h}, \mathrm{MA} 30 \mathrm{~min}$, while the matrix material was dissolved only to a limited extent (Al $2.88 \%$, Si $0.12 \%$, Ca $0.05 \%$ ). After $\mathrm{Cr}$ leaching followed by alkali washing, a carbonation treatment is proposed to stabilise the remaining $\mathrm{Cr}$ in the matrix material and make the subsequent recycling of the matrix material as a construction material possible.
\end{abstract}




\section{Introduction}

Chromium ( $\mathrm{Cr}$ ) containing slags ( $\mathrm{Cr}<2$ wt\%) such as electric arc furnace (EAF) slag or argon decarburisation (AOD) slag generated during melting or refining of stainless steel manufacturing are classified as hazardous waste (Yi et al., 2012; Zhang and Hong, 2011; Shen et al., 2004; Shen and Forssberg, 2003). Their disposal is a major environmental concern (Spooren et al., 2013; Parasad, 2010). Currently most of these materials are still disposed of in landfills or used as low-grade construction materials (Sheen et al., 2014; Gencel et al., 2013; Zhang, et al., 2013; Mesei and Elevlis, 2012).

When these waste materials are landfilled, the slag material needs to be stabilized to avoid the release of contaminants to the groundwater or soil. In the case of $\mathrm{Cr}$, several stabilization routes have been studied to transform the soluble $\mathrm{Cr}(\mathrm{VI})$ to insoluble $\mathrm{Cr}(\mathrm{III})$ by reducing agents, such as $\mathrm{FeSO}_{4}$ (Jagupilla et al, 2009), $\mathrm{Na}_{2} \mathrm{~S}$ (Velasco et al, 2012) and $\mathrm{Ca}_{5} \mathrm{~S}$ (Wazne et al, 2007), or through biological treatment (Dhal et al, 2013; Yu et al., 2012). However, stabilization to landfill is not a promising process due to the generation of large amounts of waste material, being an environmental and economic burden, and the presence of remaining soluble $\mathrm{Cr}(\mathrm{VI})$ by incomplete reduction of the $\mathrm{Cr}$.

Furthermore, due to changing economic conditions and technological innovations, these types of waste have become potential resources for the recycling and recovery of various valuable metals and critical raw materials, such as chromium (UNEP, 2013). In 2000, it was estimated that worldwide 46,000 tons of $\mathrm{Cr}$ were lost in stainless steel slags and 637,000 tons in chromite ore process residues (COPR) (Jhonson et al, 2006). When the leachable $\mathrm{Cr}$ is removed from the mineral matrix material, this material can be used as a valuable product/resource in the building industry without posing a risk to the environment. (Salman et al, 2014; Reuter et al., 2004; Shen and Forssberg, 2003). One possible route to turn slags into new building materials is through a carbonation process, which enhances the technical and environmental properties of the slag and increases its value as a construction material (Sheen et al., 2014; Quaghebeur et al., 2010; Teir et al., 2005).

The traditional recovery of $\mathrm{Cr}$ from chromite ore or $\mathrm{Cr}$ oxides involves roasting with $\mathrm{Na}_{2} \mathrm{CO}_{3}$ above $1100{ }^{\circ} \mathrm{C}$ (Dhal et al., 2013; Antony et al., 2001; Habashi, 1997; Ladd and Vanderpool, 1987). Since this process is very energy consuming, it is not applicable to low-grade ore materials. A hydrometallurgical method, based on caustic soda leaching has been applied to $\mathrm{Cr}$ recovery from chromite ore as well as chromium oxides (Habashi, 1997; Gupta and Mukherjee, 1990). Chromium oxides present in slags readily dissolve with $\mathrm{NaOH} / \mathrm{KOH}$ under oxidative pressure $\left(1-3.2 \mathrm{Mpa}\right.$ ) at $210-300{ }^{\circ} \mathrm{C}$ (Zhang et al., 2014; Xu et al., 2005, 2006; Amer and Ibrhim, 1996; Gupta and Mukherjee, 1990). This process, however, requires high pressure and a high concentration of alkaline agents (60 - $70 \mathrm{wt} \%$ ). An additional disadvantage is that this process is not applicable for subsequent matrix recycling due to the dissolution of matrix elements such as $\mathrm{Al}$ and $\mathrm{Si}$. In fact, several authors have also studied $\mathrm{Cr}$ leaching from slag materials in acidic conditions under pressurized $\mathrm{H}_{2} \mathrm{SO}_{4}$ (Jiang et al., 2014; Zhao et al., 2014) as well as $\mathrm{HCl}$ (Yang et al., 2008). However, those processes also simultaneously dissolve the stainless steel slag matrix materials, i.e. no selective $\mathrm{Cr}$ leaching takes place.

The aim of this study is to selectively remove $\mathrm{Cr}$ from a historic stainless steel (SS) slag material in order to (i) recover $\mathrm{Cr}$ from this low-grade (secondary) ore and (ii) reuse the matrix material as a resource for the production of construction materials. Alkaline pressure leaching was studied for the recovery of $\mathrm{Cr}$ using a $2^{4-1}$ factorial design to reveal the most important parameters for $\mathrm{Cr}$ leaching.

\section{Material and methods}

\subsection{Material}

A representative SS slag sample was obtained from a historic slag monolandfill. At the site, samples were collected at different positions and depths to obtain a total sample of $300 \mathrm{~kg}$. The $300 \mathrm{~kg}$ batch sample was mixed and subsamples were taken for further analysis and experiments. For this study, the slag was crushed and ground below $125 \mu \mathrm{m}$. The slags main chemical composition consists of calcium (42\% CaO), silicium (26\% $\left.\mathrm{SiO}_{2}\right)$, magnesium (11\% $\mathrm{MgO}$ ) and aluminum $\left(2.1 \% \mathrm{Al}_{2} \mathrm{O}_{3}\right)$ and some minor, but still considerable, amounts of $\mathrm{d}$ block metals, such as chromium $(1.18 \% \mathrm{Cr})$, titanium $(0.50 \% \mathrm{Ti})$, iron $(0.72 \% \mathrm{Fe})$, and manganese $(0.45 \% \mathrm{Mn})$. The mineralogical composition of the slag consists mainly of merwinite, $\mathrm{Ca}_{3} \mathrm{Mg}\left(\mathrm{SiO}_{4}\right)_{2}$, and akermanite, $\mathrm{Ca}_{2} \mathrm{Mg}\left(\mathrm{Si}_{2} \mathrm{O}_{7}\right)$ phases. Furthermore, a spinel phase was observed which could possibly be assigned to $(\mathrm{Fe}, \mathrm{Mg})(\mathrm{Cr}, \mathrm{Al}, \mathrm{Fe})_{2} \mathrm{O}_{4}$, which contains chromium. 


\subsection{Alkaline pressure leaching test}

Leaching experiments were carried out in a $100 \mathrm{~mL}$ stainless steel reactor (Premex reactor ag $^{\circledR}$ ) equipped with a digitally controlled electric heating. The reactor was purged and pressurized at room temperature with $\mathrm{O}_{2}$ as an oxidant to a predetermined amount ( 8.4 bar) after which the reactor was sealed. A mechanical agitator with a stirring speed of $200 \mathrm{rpm}$ was applied, and the reactor was heated to the desired temperature within 20 min (saturated water vapor pressure: 6.8 bar at $160{ }^{\circ} \mathrm{C}, 18.5$ bar at $200{ }^{\circ} \mathrm{C}$, and 43.0 bar at $240{ }^{\circ} \mathrm{C}$ ). During the leaching test, the pressure, consisting of the partial oxygen pressure and the autogenous water vapor pressure (measured vapor pressure: 15 bar at $160{ }^{\circ} \mathrm{C}$, 24 bar at $200{ }^{\circ} \mathrm{C}$, and 36 bar at $240{ }^{\circ} \mathrm{C}$ ), and temperature were digitally monitored and logged. After the imposed reaction time ( 3 to $6 \mathrm{~h}$ ), the reactor was cooled down to room temperature in $4 \mathrm{~h}$. Subsequently, the reactor was opened and the recovered suspension was separated in a liquid and a solid fraction by centrifuging and filtering.

For the mechanical activation (MA), dry milling was carried out using a planetary ball mill (Retsch, PM 400) with an overall capacity of $500 \mathrm{~mL}$ for 10, 15 or $30 \mathrm{~min}$ at a rotation speed of $400 \mathrm{rpm}$. After milling, the activated sample directly went to the alkaline pressure leaching step. Particle size analyses were carried out by powder laser diffraction (Microtrac S3500). Samples were analyzed by the wet method through dispersion in deionized water (L/S 20) after sonication for $5 \mathrm{~min}$.

\section{Preliminary test}

In order to select the most suitable reagent and concentration range for the experimental design, alkaline leaching was investigated with different alkaline agents, such as $\mathrm{Na}_{2} \mathrm{CO}_{3}$ and $\mathrm{NaOH}$, and concentrations of these reagents between 0.02 and $1 \mathrm{M}$.

\section{Experimental design}

Based on the preliminary results, further $\mathrm{Cr}$ leaching experiments with SS slag were performed according to a design of experiment (DOE). The applied design includes 4 independent parameters that are each tested at two levels (low and high, coded -1 and +1 respectively), namely temperature $\left(160,240{ }^{\circ} \mathrm{C}\right)$, leaching time $(3,6 \mathrm{~h})$, $\mathrm{NaOH}$ concentration $(0.5,1 \mathrm{M})$, and mechanical activation $(\mathrm{MA})$ time $(0,30 \mathrm{~min})$. The aim of this design model is to identify which factors have a significant effect on $\mathrm{Cr}$ leaching. Therefore a fractional factorial $\left(2^{4-1}\right)$ design of experiments was adopted, requiring just 8 experiments. This implies that higher order effects like three-way interactions are negligible compared to the main effects, a concept known as sparsity. In addition, two center point (replicate) observations (parameter values in between high and low values, coded 0) were added to the design to assess the linearity assumption. The obtained experimental results were processed using the Minitab 14 statistical software. The analysis of variance (ANOVA) was performed to assess the main effects of the investigated factors, their importance in the regression model as well as the lack of fit and curvature significance.

The change of standard Gibbs energy for $\mathrm{Cr}_{2} \mathrm{O}_{3}$ or spinel structure reaction with alkaline agents or oxygen as an oxidant was calculated using HSC software (2002).

\subsection{Environmental and carbonation testing}

\section{Preliminary washing}

The obtained residue after APL was washed at a liquid to solid (L/S) ratio of 20 with various washing agents, such as water with sonication in an ultrasonic bath, $\mathrm{NaOH}$, and $\mathrm{HCl}$ at $25^{\circ} \mathrm{C}$ for $1 \mathrm{~h}$. Subsequently, the washed residue was dried at $105^{\circ} \mathrm{C}$ for $6 \mathrm{~h}$ prior to performing a one stage leaching test. 


\section{One stage leaching test}

In order to determine the metal leachability from the residues of the APL before and after carbonation of the residue, batch leaching tests were performed based on the European Standard EN 12457-2 (2002) leaching test method. During this test 2.0 gram of solid material was mixed with $20 \mathrm{~mL}$ ultrapure water $(18.2 \mathrm{M} \Omega \cdot \mathrm{cm})(\mathrm{L} / \mathrm{S}$ ratio 10) in a $100 \mathrm{~mL}$ Pyrex beaker, and stirred with a magnetic stir bar at $200 \mathrm{rpm}, 25{ }^{\circ} \mathrm{C}$ for $24 \mathrm{~h}$. The leaching solution was filtered with a $0.45 \mu \mathrm{m}$ membrane filter for subsequent ICP-AES analysis.

\section{Carbonation test}

The APL residue after washing with $0.1 \mathrm{M} \mathrm{NaOH}$ and drying was used for the carbonation experiments. The leaching residue was mixed with $10 \mathrm{wt} \%$ water and compressed in a cylindrical mold with a diameter of $25 \mathrm{~mm}$ using a compaction force of $175 \mathrm{~kg}_{\mathrm{f}} / \mathrm{cm}^{2}$. The final height of the cylinders was $11 \mathrm{~mm}$, and the bulk density was $2.33 \mathrm{~g} / \mathrm{cm}^{3}$. Carbonation of the cylinders was carried out in a reactor at 20 bar $\mathrm{pCO}_{2}$ (with automatic replenishment of the consumed $\mathrm{CO}_{2}$ ) and at $80{ }^{\circ} \mathrm{C}$ for $8 \mathrm{~h}$ according to the Carbstone process (Quaghebeur et al., 2009; Quaghebeur et al., 2010). The compressive strength of the carbonated cylinders was measured. For the leaching tests the carbonated samples were crushed and milled to obtain a similar grain size as that of the original material $(<125 \mu \mathrm{m})$.

\subsection{Analytical methods}

The total concentration of chromium and other matrix elements in the leach liquor was determined by inductively coupled plasma atomic emission spectroscopy (ICP-AES, Thermo Elemental). The chemical compositions of the residue and raw material samples $(<125 \mu \mathrm{m})$ were determined by X-ray fluorescence (XRF, Thermo Scientific) and ICP-AES after microwave digestion of the sample with $\mathrm{HCl}, \mathrm{HNO}_{3}$, and $\mathrm{HF}$ (described in method CMA/2/II/A.3, VITO, 2005). Mineralogical analyses were performed using X-ray diffraction (XRD, Philips). The morphology of the sample and distribution of the $\mathrm{Cr}$ therein were determined using scanning electron microscopy (SEM, FEI) and energy dispersive X-ray (EDS, Bruker), respectively. For SEM analysis, samples were embedded in an epoxy resin, polished to produce a smooth, flat surface, and coated with a thin PdPt (80:20wt\%) layer.

\section{Results and discussion}

\subsection{Slag characterization}

SEM images of the stainless steel slag (Fig 1) indicate that $\mathrm{Cr}$ is mainly present in both spinel and FeCr alloy phases. The spinel phases have small dimensions $(<10 \mu \mathrm{m})$ and are embedded in calcium silicate matrix phases (Fig. 1a), while the FeCr iron rich alloy phases (Fig. 1b) are present as metal droplets $(<20 \mu \mathrm{m})$.

\subsection{Thermodynamic analysis}

The changes of standard Gibbs energy for $\mathrm{Cr}_{2} \mathrm{O}_{3}$ oxidation reaction with oxygen in the absence (Eq. 1) and presence of different alkaline agents (Eqs. 2-3) were calculated at standard states. The results show that the Gibbs free energy of reactions 2 and 3 is negative, meaning that the oxidation of $\mathrm{Cr}(\mathrm{III})$ to $\mathrm{Cr}(\mathrm{VI})$ occurs relatively easy in the presence of $\mathrm{Na}_{2} \mathrm{CO}_{3}$ and $\mathrm{NaOH}$. Furthermore, at standard states the presence of $\mathrm{NaOH}$ is preferable because the reaction is characterized by a lower Gibbs free energy (Eq. 3). On the other hand, oxidation cannot occur thermodynamically at standard states without an alkaline agent (positive Gibbs free energy for Eq. 1). It shows that an alkaline agent, especially $\mathrm{NaOH}$, is an important factor in oxidative $\mathrm{Cr}$ leaching at relatively low temperatures (Zydorczak et al, 2012; Qi et al., 2011; Xu et al, 2005). 


$$
\begin{array}{ll}
\mathrm{Cr}_{2} \mathrm{O}_{3}+1.5 \mathrm{O}_{2(\mathrm{~g})}=2 \mathrm{CrO}_{3} & \Delta \mathrm{G}^{0}{ }_{298 \mathrm{~K}}=12.11 \mathrm{kcal} / \mathrm{mol} \\
\mathrm{Cr}_{2} \mathrm{O}_{3}+1.5 \mathrm{O}_{2(\mathrm{~g})}+2 \mathrm{Na}_{2} \mathrm{CO}_{3}=2 \mathrm{Na}_{2} \mathrm{CrO}_{4}+2 \mathrm{CO}_{2(\mathrm{~g})} & \Delta \mathrm{G}^{0}{ }_{298 \mathrm{~K}}=-26.11 \mathrm{kcal} / \mathrm{mol} \\
\mathrm{Cr}_{2} \mathrm{O}_{3}+1.5 \mathrm{O}_{2(\mathrm{~g})}+4 \mathrm{NaOH}=2 \mathrm{Na}_{2} \mathrm{CrO}_{4}+2 \mathrm{H}_{2} \mathrm{O} & \Delta \mathrm{G}^{0}{ }_{298 \mathrm{~K}}=-89.01 \mathrm{kcal} / \mathrm{mol}
\end{array}
$$

However, in the stainless steel slag $\mathrm{Cr}(\mathrm{III})$ is not present in $\mathrm{Cr}_{2} \mathrm{O}_{3}$ but rather in more complex spinel phases. Compared to the $\mathrm{Cr}_{2} \mathrm{O}_{3}$ phase, the spinel $\mathrm{MgCr}_{2} \mathrm{O}_{4}$ (Eq. 4) is more stable having less negative Gibbs free energy during oxidation in the presence of $\mathrm{NaOH}$, while $\mathrm{FeCr}_{2} \mathrm{O}_{4}$ (Eq. 5) is more easily dissolved than $\mathrm{Cr}_{2} \mathrm{O}_{3}$. Furthermore, the change in Gibbs free energy of $\mathrm{Cr}(\mathrm{VI})$ in $\mathrm{CaCrO}_{4}$ (Eq. 6) upon reaction with $\mathrm{NaOH}$ is less negative than for Eq. (4) and (5), which indicates that $\mathrm{CaCrO}_{4}$ is more stable and difficult to dissolve. These trends are also shown in the E-pH diagrams in Fig. 2. The $\mathrm{Cr}$ (III) solid phases, $\mathrm{Cr}_{2} \mathrm{O}_{3}$ (Fig. 2a), $\mathrm{MgCr}_{2} \mathrm{O}_{4}$ (Fig. 2c) and $\mathrm{FeCr}_{2} \mathrm{O}_{4}$ (Fig. $2 \mathrm{~d}$ ) are very stable in the entire $\mathrm{pH}$ region except under strong acidic conditions $(\mathrm{pH}<2)$. This indicates that an oxidation regime is needed to dissolve these phases.

$$
\begin{aligned}
& \mathrm{MgCr}_{2} \mathrm{O}_{4}+4 \mathrm{NaOH}+1.5 \mathrm{O}_{2(\mathrm{~g})}=2 \mathrm{Na}_{2} \mathrm{CrO}_{4}+2 \mathrm{H}_{2} \mathrm{O}+\mathrm{MgO} \quad \Delta \mathrm{G}^{0}{ }_{298 \mathrm{~K}}=-76.94 \mathrm{kcal} / \mathrm{mol} \text { (4) } \\
& \mathrm{FeCr}_{2} \mathrm{O}_{4}+4 \mathrm{NaOH}+1.75 \mathrm{O}_{2(\mathrm{~g})}=2 \mathrm{Na}_{2} \mathrm{CrO}_{4}+2 \mathrm{H}_{2} \mathrm{O}+\mathrm{Fe}_{2} \mathrm{O}_{3} \quad \Delta \mathrm{G}^{0}{ }_{298 \mathrm{~K}}=-105.18 \mathrm{kcal} / \mathrm{mol}(5) \\
& \mathrm{CaCrO}_{4}+2 \mathrm{NaOH}=\mathrm{Na}_{2} \mathrm{CrO}_{4}+\mathrm{H}_{2} \mathrm{O}+\mathrm{CaO} \quad \Delta \mathrm{G}^{0}{ }_{298 \mathrm{~K}}=-3.19 \mathrm{kcal} / \mathrm{mol} \quad(6)
\end{aligned}
$$

\subsection{Alkaline pressure leaching (APL)}

Zydorczka et al. (2012) have shown that at atmospheric conditions the alkaline leaching of $\mathrm{Cr}$ (III) from oxides is very low and the reaction is slow. Therefore, we investigated $\mathrm{Cr}$ leaching in oxidative pressurized conditions at elevated temperature, which should improve the thermodynamics and kinetics of $\mathrm{Cr}$ dissolution. In a preliminary test, $\mathrm{Cr}$ slag was leached with different alkaline agents, such as $\mathrm{Na}_{2} \mathrm{CO}_{3}$ and $\mathrm{NaOH}$, and at various $\mathrm{NaOH}$ concentrations in the presence of oxygen gas, in order to establish the preferred reagent and concentration range for a further design of experiment. The obtained $\mathrm{Cr}$ leachabilities in these preliminary tests are shown in the supplementary data (SD) section (Fig. I). As predicted by the thermodynamic analysis (Eqs. 1$3), \mathrm{Cr}$ leaching was not efficient in the presence of only oxygen. The addition of $\mathrm{Na}_{2} \mathrm{CO}_{3}$ and $\mathrm{NaOH}$ at stoichiometric amounts according to Eq. 2 and 3 slightly increased the $\mathrm{Cr}$ leachability to $5.5 \%$ and $6.0 \%$, respectively. However, when the concentration of $\mathrm{NaOH}$ was increased to $1 \mathrm{M}, \mathrm{Cr}$ leaching was drastically enhanced to $20 \%$ due to increasing ionic activity and diffusivity of $\mathrm{NaOH}$.

Based on the preliminary results described above, the influence of reaction parameters and conditions on selective $\mathrm{Cr}$ leaching in the presence of $\mathrm{NaOH}$ and $\mathrm{O}_{2}$ were assessed by a DOE method. Mechanical activation (MA) was introduced as a parameter, since MA by milling is well known to improve the extraction of metal components from minerals (Baláž, 2000). Mechanical activation leads to amorphization of the mineral material by disordering its crystal structure or inducing phase transitions, causing a more facile decomposition (Baláž, 2000). Also, the decomposition temperature of minerals can be reduced by MA during milling (Baláž, 2000, 2008). Zhang et al. (2010) enhanced $\mathrm{Cr}$ leaching from chromite ore in molten $\mathrm{NaOH}$ by applying MA. They observed an extraction efficiency of $97 \%$ after MA for 10 min and leaching for $200 \mathrm{~min}$.

Table 1 presents the used DOE arrangement and the obtained response (Cr leaching (\%) results). The ANOVA test was used to analyze the importance of each term in the regression model as well as the lack of fit and curvature significance. The test shows that the factors temperature and MA have a significant effect $(p<0.05)$ on $\mathrm{Cr}$ leaching. For the factors time $(p=0.085)$ and $\mathrm{NaOH}$ concentration $(p=0.14)$ no significant effect could be concluded at a $95 \%$ confidence level. After removal of the non-significant parameters, time and $\mathrm{NaOH}$ concentration, a final regression model is made which yields the following equation in coded variables: 
This relation shows that the temperature (coefficient 11.46) has the most significant effect on $\mathrm{Cr}$ leaching, followed by mechanical activation time (coefficient 5.31). Since both coefficients are positive, both factors show an increase of $\mathrm{Cr}$ leaching when increased (Fig. 3). The results of the ANOVA test on the regression model are reported in the supplementary data (Table I). The linear model above can explain the observations for $64 \%$ as is indicated by the adjusted $\mathrm{R}^{2}$. Also, the lack-of-fit is considered non-significant $(p=0.206)$, indicating a good fit of the observed data to the regression model. However, the ANOVA test also indicates that a significant curvature is present $(p=0.012<0.05)$. This is reflected in an underestimation of the $\mathrm{Cr}$ leaching at the center point.

With the results above and the chosen experimental design it is impossible to find the optimum parameters for $\mathrm{Cr}$ leaching. For this purpose, the design should be extended to a response surface design (e.g. central composite or Box-Behnken) for which additional experiments will have to be carried out in a follow-up study.

An additional experiment was performed in which MA was carried out for 10, 15 and 30 minutes to investigate whether the MA time could be reduced without having a large effect on $\mathrm{Cr}$ leaching was investigated (Fig. Ila in $\mathrm{SD}$ ) in the highest $\mathrm{Cr}$ recovery in DOE (i.e. $240{ }^{\circ} \mathrm{C}, 6 \mathrm{~h}$ and $1.0 \mathrm{M} \mathrm{NaOH}$ ). The $\mathrm{Cr}$ leaching increases from $31 \%$ to $46 \%$ by increasing the MA time from 10 to $30 \mathrm{~min}$. After a MA time of 15 minutes the $\mathrm{Cr}$ leaching already reached $43 \%$. 15 minutes of MA is thus sufficient to obtain similar results as with 30 minutes MA. The particle size distribution after 15 and 30 minutes MA are similar (Fig. Ilb in SD). The effect of MA on the crystallinity of the composing minerals of the SS slag was investigated and is shown in the supplementary data section (Fig. III). As the MA time was increased the XRD peaks were broadened and less intense, which indicates a decrease of crystallinity (and crystal sizes) and thus amorphization of the material (Baláž, 2000, 2008).

The effect of particle size (without MA) was investigated by comparing $\mathrm{Cr}$ leaching from the SS slag after sieving the raw material below $32 \mu \mathrm{m}$ to the $<125 \mu \mathrm{m}$ fraction used elsewhere (Fig. Ila in SD). It was shown that the $\mathrm{Cr}$ leaching for the $<32 \mu \mathrm{m}$ SS slag was higher (34\%) than that of $<125 \mu \mathrm{m}$ fraction (24\%), and similar to that when MA of 10 min was applied on the raw $(<125 \mu \mathrm{m})$ material (31\%) (Fig. Ila in SD). Therefore, it can be concluded that the main effect of MA on the $\mathrm{Cr}$ leachability is due to a decrease in particle size, or rather the increase of the effective surface area of $\mathrm{Cr}$ oxides by liberation. This is confirmed by the particle size (Fig. IIb in SD) which is similar for the < $32 \mu \mathrm{m}$ and MA 10 min samples, whereas the $<125 \mu \mathrm{m}$ sample is much coarser. The increase of $\mathrm{Cr}$ leaching in MA 15 min to 43\% may be attributed to armorphization (i.e. structure disordering or defects). This is confirmed by XRD analyses in function of MA time (Fig. III in SD) indicating decreased intensity and broadening of peaks as of MA $15 \mathrm{~min}$.

Furthermore, the effect of liquid to solid (L/S) ratio was investigated by decreasing L/S ratio from 10 to 5 . An decreased $\mathrm{L} / \mathrm{S}$ ratio can reduce both the reagent consumption and required reactor size, leading to better economics of the process. Generally, L/S ratio can be optimized after the affecting parameters and conditions of the process are optimized and selected (Gupta and Mukherjee, 1990; Habashi, 1997). So, the effect of the $\mathrm{L} / \mathrm{S}$ ratio on $\mathrm{Cr}$ leaching was studied at the maximum $\mathrm{Cr}$ leaching condition in our study $\left(240{ }^{\circ} \mathrm{C}, 1 \mathrm{M} \mathrm{NaOH}, \mathrm{MA}\right.$ $30 \mathrm{~min}, 6 \mathrm{~h}$ ). These experiments were not included in the DOE design. The experiments show that the leaching of $\mathrm{Cr}$ drastically decreased from $46.0 \%$, to $32.6 \%$ and $23.8 \%$ as the $\mathrm{L} / \mathrm{S}$ ratio decreased from 10 to 6 and 5 , respectively. Therefore, a lower $\mathrm{L} / \mathrm{S}$ is disadvantageous for $\mathrm{Cr}$ leaching and L/S 10 is the optimum L/S ratio within the tested range.

During the APL at optimal condition $\left(240{ }^{\circ} \mathrm{C}, 6 \mathrm{~h}, \mathrm{MA} 30 \mathrm{~min}, 1 \mathrm{M} \mathrm{NaOH}, \mathrm{L} / \mathrm{S} 10,8.4\right.$ bar $\left.\mathrm{pO}_{2}\right)$, the leachability of other elements present in the slag was analyzed (Table II in SD). These analyses showed that most of the elements were not dissolved from the slag. The maximum leaching was observed for Al reaching $2.88 \%$. The presence of $\mathrm{Na}$ in the residue originates from the used alkaline agent, $\mathrm{NaOH}$, which remained in concentrations of around $0.8 \%$.

\subsection{Residue utilization}




\subsubsection{Residue analysis}

As observed with the SEM, Cr is mainly present in spinel structures and Fe alloys, which are evenly distributed in the silicate matrix of the SS slag (Fig. 1). Shen et al (2004) reported that in stainless steel slag more than $70 \%$ of $\mathrm{Fe}$ and $\mathrm{Cr}$ are generally present in the form of oxides (spinel). The alloy phases are stable in alkaline conditions because a passivation layer of $\mathrm{Cr}$ (III) oxide or Fe oxides (Kim et al., 2015) is formed. This is also in accordance with the E-pH diagram presented in Fig. 2.

The SEM/BSE images and EDS mappings of the APL residue (Fig. IV in SD) clearly show that the surface layer of the slag particles has been leached and subsequently covered by new precipitates. The leached layer is the darker (less dense) layer at the surface of the slag particles. The new precipitates, on the other hand, are denser (lighter colored in the SEM/BSE images) than the slag particles. These precipitates are rich in $\mathrm{Ca}, \mathrm{Al}$ and $\mathrm{Si}$, but contain no or very little Mg. Based on the SEM/BSE images (high density and crystal form), the SEM/EDS mapping and the XRD pattern of the residue (Fig. $\mathbf{V}$ in SD) it can be concluded that these precipitates are most likely hibschite, $\mathrm{Ca}_{3} \mathrm{Al}_{2}\left(\mathrm{SiO}_{4}\right)_{2}(\mathrm{OH})_{4}$. Hibschite may form during APL by hydrothermal reaction with the slag particles. The precipitation of this mineral has been shown to induce hydrothermal solidification of blast furnace slag (Hosokawa et al., 2014). Here, hibschite seems to form a layer around the slag particles, which may hamper the leaching of the underlying slag particles.

XRD patterns of the raw SS slag, and the residue after APL and carbonation are all shown in the supplementary data section (Fig. V). In the APL residue the remains of the silicate minerals akermanite, $\mathrm{Ca}_{2} \mathrm{Mg}\left(\mathrm{Si}_{2} \mathrm{O}_{7}\right)$, and monticelite, $\mathrm{CaMgSiO}_{4}$ can still be observed. Other silicates such as merwinite, $\mathrm{Ca}{ }_{3} \mathrm{Mg}\left(\mathrm{SiO}_{4}\right)_{2}$ have almost disappeared completely. In the residue also newly formed mineral phases such as hibschite, $\mathrm{Ca}_{3} \mathrm{Al}_{2} \mathrm{Si}_{2} \mathrm{O}_{8}(\mathrm{OH})_{4}$ and calcium silicate hydrate phases are present.

\subsubsection{Leachability test}

The environmental impact of the residue was investigated by performing a one-stage leaching test to investigate $\mathrm{Cr}$ leachability of the residue after $\mathrm{APL}\left(1 \mathrm{M} \mathrm{NaOH}, 240{ }^{\circ} \mathrm{C}, 6 \mathrm{~h}, \mathrm{MA} 30 \mathrm{~min}, \mathrm{~L} / \mathrm{S} \mathrm{10}\right)$. Before the leaching test the APL residue was washed with various washing agents such as water with sonication (No. 1) in an ultrasonic bath, $0.1 \mathrm{M} \mathrm{NaOH}$ (No. 2), and $0.1 \mathrm{M} \mathrm{HCl}$ (No. 3) to remove adsorbed or unrinsed $\mathrm{Cr}(\mathrm{VI})$. $\mathrm{The}$ results of these tests are shown in Table III (in SD). Clearly, water washing assisted by sonication was the most effective method for $\mathrm{Cr}$ removal. During $\mathrm{NaOH}$ washing the amount of $\mathrm{Cr}$ in the leachate (washing water) is $40 \%$ lower than for the water washed material. However, during $\mathrm{NaOH}$ washing far less $\mathrm{Ca}$ leaching is observed. Because $\mathrm{Ca}$ is as an important resource for the carbonation reactions that bind the slag particles together to produce a brick like building material, $\mathrm{NaOH}$ washing is considered more promising. $\mathrm{NaOH}$ has also been reported to enhance carbonation, either by enhancing the extraction of $\mathrm{Ca}$ - and/or Mg-ions from silicate structures (Blencoe et al., 2004) or by enhancing $\mathrm{CO}_{2}$ dissolution and precipitation of carbonates (MontesHernandez et al., 2012), thus if some $\mathrm{NaOH}$ remains in the residue this may also be beneficial for the subsequent carbonation process.

After washing the residue under different conditions, a one-stage leaching test was performed by stirring the residue in water (L/S 10) for $24 \mathrm{~h}$ in accordance with EN 12457-2 (2002). The results for the water washed and $\mathrm{NaOH}$ washed samples were compared (Table 2). Both alkali pressure leached and subsequently washed materials (No. 1,2) exceeded the legal limit value for $\mathrm{Cr}$ leaching for reuse as construction materials in the Flemish region of Belgium ( $0.5 \mathrm{mg} / \mathrm{kg} \mathrm{dm}$ ). However, washing with $0.1 \mathrm{M} \mathrm{NaOH}$ (No. 2) was the most effective treatment to reduce $\mathrm{Cr}$ leaching to $0.84 \mathrm{mg} / \mathrm{kg} \mathrm{dm}$. Note, that the leaching results of the EN 12457-2 batch leaching test can only be used as an indicative value for comparison with the Flemish leaching limit values. To test whether a material complies with the Flemish leaching limit values a column leaching test in accordance with NEN 7373 (2003) has to be performed. The NEN 7373 and EN 12457-2 leaching tests are both carried out at a $\mathrm{L} / \mathrm{S}$ ratio of 10 , with material $<4 \mathrm{~mm}$. The major difference is that the EN 12457-2 test is carried out under 
vigorous shaking during 24 hours, while the NEN 7373 test is a column leaching test that takes 21 days to perform. In many cases the leaching concentrations obtained by both tests are comparable if the same L/S ratio is applied (Grathwohl and Susset, 2009).

\subsubsection{Carbonation of the residue}

XRD patterns before and after carbonation were measured and are shown in the supplementary data section (Fig. V). The hydroxyl form, hibschite, disappeared after carbonation indicating that the Ca present in hibschite was converted to carbonates, which was confirmed by the increasing intensity of the $\mathrm{CaCO}_{3}$ diffraction peaks. The intensities of the akermanite diffraction peaks, on the other hand, were not affected by the carbonation process.

Compressive strength is one of the most important mechanical properties of building materials. The compressive strength of the carbonated sample was $38 \mathrm{MPa}$. The minimum compressive strength of limestone building stones varies from approximately $17 \mathrm{MPa}$ to $55 \mathrm{MPa}$ based on the density (Ingham, 2011). The carbonated sample thus fulfills the criteria for low and medium density limestones (> $28 \mathrm{MPa}$ ). Therefore, it could be applied for various building applications.

When the one-stage leaching test was performed on the carbonated sample, the $\mathrm{Cr}$ leaching was reduced to $0.43 \mathrm{mg} / \mathrm{kg} \mathrm{dm}$, which is below the legal leaching limit value of $0.5 \mathrm{mg} / \mathrm{kg} \mathrm{dm}$ in the Flemish region of Belgium (VLAREMA, 2012). This indicates that reuse as a construction material may be possible in the Flemish region of Belgium (Spooren et al., 2013). This also clearly shows that besides the technical benefits, carbonation also enhances the stabilization of $\mathrm{Cr}$ in the residue and thereby decreases the associated environmental risks.

\subsection{Suggested process}

Based on the results of the Cr leaching experiments, we propose a SS slag recycling process as shown in Fig. 4. This process will result in the recovery of valuable $\mathrm{Cr}$ as well as the matrix material from which the $\mathrm{Cr}$ content, a hazardous pollutant, is reduced. This matrix material can be further recycled after washing steps with alkali and water by means of a carbonation process. Carbonation allows for $\mathrm{Ca}$ - and Mg-containing slag materials to be shaped and solidified to generate strong building products, whereby $\mathrm{Ca}$ - and Mg-carbonates act as a binding agent. Furthermore, the remaining $\mathrm{Cr}$ in the matrix is stabilized by this process and leaching is reduced below legal limit values for the Flemish region of Belgium. Chromium can be recovered from the leachate and the alkali/water washing solution by a Cr recovery processes, such as ion exchange (Sengupta et al., 1986; Gode and Pehlivan 2005) or (electro-)reduction/precipitation (Golder et al., 2011; Ramakrishnaiah, 2012).

\section{Conclusions}

In this study an effective hydrometallurgical recovery of $\mathrm{Cr}$ from historic stainless steel slags was developed. Selective $\mathrm{Cr}$ leaching by alkaline pressurized oxidation, combined with a mechanical activation pre-treatment step was investigated. Based on the experimental results, the following conclusions are drawn.

(1) The stainless steel slag matrix is composed of more than $90 \mathrm{wt} \%$ calcium silicates containing crystalline phases such as merwinite, $\mathrm{Ca}_{3} \mathrm{Mg}\left(\mathrm{SiO}_{4}\right)_{2}$, and akermanite, $\mathrm{Ca}_{2} \mathrm{Mg}\left(\mathrm{Si}_{2} \mathrm{O}_{7}\right)$. Embedded in the matrix, 1.2 wt\% chromium is present, mainly as fine grained oxides (spinels) or $\mathrm{FeCr}$ metallic droplets.

(2) The leaching efficiency of $\mathrm{Cr}$ under alkaline oxidizing conditions increased with temperature and MA time, which were determined to be the most significant parameters by a DOE. Maximum $\mathrm{Cr}$ leaching was $46 \%$ at the condition of $240{ }^{\circ} \mathrm{C}, 6 \mathrm{~h}, \mathrm{MA} 30 \mathrm{~min}, 1 \mathrm{M} \mathrm{NaOH}, \mathrm{L} / \mathrm{S} 10,8.4$ bar $\mathrm{pO}_{2}$ with limited dissolution of matrix elements (Al 2.88\%, Si 0.12\%, Ca 0.05\%).

(3) In the leaching residue, precipitation of hibschite on the surface of the leached slag particles was observed. These precipitates may hamper further $\mathrm{Cr}$ leaching of the underlying slag particles during APL.

(4) For a complete recycling of the stainless steel slag, we propose a recycling process which closes the full material loop. After $\mathrm{Cr}$ leaching by the MA assisted APL technique and a subsequent washing step the leftover matrix material can be used for the production of building materials through a carbonation step. 
Chromium can be recovered from the leachate and alkali/water washing solution by ion exchange or precipitation.

\section{Acknowledgements}

This project has received European Regional Development Funding through INTERREG IVB "Investing in opportunities". This work was supported by the RENEW Project (INTERREG IVB NWE Programme) (ref. 317JRENEW)."

Our colleague, Koen Michiels (VITO) is acknowledged for his helpful discussions on DOE and statistics. We sincerely thank Centre Terre et Pierre (Tournai, Belgium) to provide us with the SS slag samples and Myrjam Mertens (VITO) for performing XRD measurements.

\section{References}

Amer, A.M., Ibrhim, I.A., 1996. Leaching of a low grade Egyptian chromite ore. Hydrometallurgy 43, 307-316.

Antony, M.P., et al., 2001. The soda-ash roasting of chromite ore processing residue for the reclamation of chromium. Metall.Mater.Trans. 32B, 987-995.

Baláž, P., 2000. Extractive metallurgy of activated minerals. $1^{\text {st }}$ ed., Elsevier Science B.V., Amsterdam.

Baláž, P., 2008. "Applied Mechanochemistry" in Mechanochemistry in Nanoscience and Minerals Engineering. Springer, Berlin, pp. 297-405.

Blencoe, J.G., Palmer, D.A., Anovitz, L.M., Beard, J.S., 2004, Carbonation of metal silicates for long-term $\mathrm{CO}_{2}$ Sequestration. Patent application WO 2004/094043.

Dhal, B., et al., 2013. Chemical and microbial remediation of hexavalent chromium from contaminated soil and mining/metallurgical solid waste: A review. J. Hazard. Mater. 250-251, 272-291.

EN 12457-2, 2002. "Characterization of waste-leaching-compliance test for leaching of granular waste materials and sludges-part 2: one stage batch test at a liquid to solid ratio of $10 \mathrm{l} / \mathrm{kg}$ for materials with particle size below $4 \mathrm{~mm}$ (without or with size reduction)". European Committee for Standardization.

Gencel, O., et al, 2013. Properties of bricks with waste ferrochromium slag and zeolite. J. Clean. Prod. 59, 111119.

Grathwohl, P., B. Susset, 2009 Comparison of percolation to batch and sequential leaching tests: Theory and data. Waste Management, 29, 2681-2688.

Gode, F., Pehlivan,E., 2005. Removal of $\mathrm{Cr}(\mathrm{VI})$ from aqueous solution by two Lewatit-anion exchange resins, Journal of hazardous materials B, 119, pp. 175-182.

Golder,A.K., et al., 2011. Removal of hexavalent chromium by electrochemical reduction-precipitation: Investigation of process performance and reaction stoichiometry, Separation and purification technology, 76, 345-350.

Gupta, C.K., Mukherjee, T.K., 1990. Hydrometallurgy in Extraction Processes Vol. I. CRC press Inc., Boca Raton, pp. 132-133.

Habashi, F., 1997. Handbook of Extractive Metallurgy IV. Wiley-VCH, New York, pp. 1761-1811.

HSC Chemistry 5.0, 2002. Chemical Reaction and Equilibrium Software with Extensive thermochemical Database. ver.5.11. Outokumpu Research Oy, Piori, Finland.

Ingham, J.P., 2011. Geomaterials under the microscope. Manson publishing, London, pp. 21-23.

Jagupilla, S.C., et al., 2009. Effects of particle size and acid addition on the remediation of chromite ore processing residue using ferrous sulfate. J. Hazard. Mater. 168, 121-128.

Jhonson, J., Schewel, L., Graedel, T.E., 2006. The contemporary anthropogenic chromium cycle. Environ. Sci. Technol. 40, 7060-7069.

Jiang, M., et al., 2014. Sulfuric acid leaching of south African chromite. Part 2: optimization of leaching conditions. Int. J. Miner. Process. 130, 102-107.

Hosokawa, M., et al., 2014. Surface reaction of blast furnace slag under hydrothermal conditions, ISIJ International. 54, 548-552.

Kim E. et al., 2015. Selective recovery of $\mathrm{Cr}$ from stainless steel slag by alkaline roasting-water leaching. Hydrometallurgy. 158, 139-148.

Ladd, J.A., Vanderpool, C.D., 1987. Process for recovery of chromium. US patent No. 4,668,483. 
Mesei, B., Elevlis, S., 2012. Recycling of chromite waste for concrete: full factorial design approach. Int. J. Environ. Res. 6, 145-150.

Montes-Hernandez, F. Renard, R. Chiriac, N. Findling and F. Toche, 2012 rapid precipitation of magnesite microcrsytals from $\mathrm{Mg}(\mathrm{OH}) 2-\mathrm{H} 2 \mathrm{O}-\mathrm{CO} 2$ slurry enhanced by $\mathrm{NaOH}$ and a heat-aging step (from 20 to $90^{\circ} \mathrm{C}$ ). Cryst. Growth Des. 2012, 12, 5233-5240.

Parasad, S., 2010. Kinetics of chromium extraction as sodium chromate from stainless steel dust. Proceedings of the XI international seminar on mineral processing technology (MPT-2010), pp. 788-796.

Qi, T., et al., 2011. Thermodynamics of chromite ore oxidative roasting process. J.Cent.South Univ. Technol. 18, 83-88.

Quaghebeur, M., Laenen, B. and Nielsen, P., 2009. Production of a mainly carbonate bonded article by carbonation of alkaline materials. WO2009/1331202.

Quaghebeur, M., et al., 2010. Carbstone: sustainable valorisation technology for fine grained steel slags and $\mathrm{CO}_{2}$. Refractories Worldforum 2, 75-79.

Ramakrishnaiah,C.R., 2012. Hexavalent chromium removal from industrial wastewater by chemical precipitation method, International journal of engineering research and applications (IJERA), 2, pp. 599603.

Reuter, M., Xiao, Y., Boin, U., 2004. Recycling and environmental issues of metallurgical slags and salt fluxes, VII International Conference in Molten slags fluxes and salts, The south African institute of mining and mineralogy, pp. 349-356.

Salman, M., et al., 2014. Effect of accelerated carbonation on AOD stainless steel slag for its valorization as a CO2-sequestering construction material. Chem. Eng. J. 246, 39-52.

Sengupta,A.K., et al., 1986. Chromate ion-exchange process at alkaline pH, Wat.Res., 20, pp. 1177-1184.

Sheen, Y.-N., Wang, H.-Y., Sun, T.-H., 2014. Properties of green concrete containing stainless steel oxidzing slag resource materials. Constr. Build. Mater. 50, 22-27.

Shen, H., and Forssberg, E., 2003. An overview of recovery of metals from slag. Waste Manage. 23, 933-949.

Shen, H., Forssberg, E. Nordström, U., 2004. Physicochemical and mineralogical properties of stainless steel slags oriented to metal recovery. Resour. Conserv. Recy. 40, 245-271.

Spooren, J., et al., 2013. Material recovery and upcycling within the ELFM concept of the REMO case, $2^{\text {nd }}$ International Academic Symposium on Enhanced Landfill Mining, Houthalen-Helchteren.

Teir, S., Eloneva, S., Zevenhoven, R., 2005. Production of precipitated carbonate from calcium silicates and carbon dioxide. Energ. Convers. Manage. 46, 2954-2979.

UNEP, 2013. Metal recycling-opportunities, limits, infrastructure, available at http://www.unep.org/resourcepanel/Publications/MetalRecycling/tabid/106143/Default.aspx

Velasco, A., et al., 2012. Pilot scale treatment of chromite ore processing residue using sodium sulfide in single reduction and coupled reduction/stabilization processes. J. Hazard. Mater. 207-208, 97-102.

VLAREMA, 2012. Besluit van de Vlaamse Regering tot vaststelling van het Vlaams reglement betreffende het duurzaam beheer van materiaalkringlopen en afvalstoffen. 17 February 2012.

Consulted at: http://navigator.emis.vito.be/milnav-consult/

VITO, 2005. Compendium voor monsterneming en analyze (CMA) in uitvoering van het afvalstoffendecreet en het bodemsaneringsdecreet. CMA/2/II/A.3 Gesloten en semi-open microgolfoven destructiemethode met salpeterzuur, zoutzuur en waterstoffluoride, July 2005.

Wazne, M., et al., 2007. Assessment of calcium polysulfide for the remediation of hexavalent chromium in chromite ore processing residue (COPR). J. Hazard. Mater. 143, 620-628.

$\mathrm{Xu}$, H.B., et al., 2005. Oxidative leaching of a Vietnamese chromite ore in highly concentrated potassium hydroxide aqueous solution at $300^{\circ} \mathrm{C}$ and atmospheric pressure. Miner. Eng. 18, 527-535.

$\mathrm{Xu}$, H.B., et al., 2006. Development of a new cleaner production process for producing chromic oxide from chromite ore. J. Clean. Prod. 14, 211-219.

Yang, Z.H., et al., 2008. Selective leaching of chromium-containing slag by HCl. J.Cent.South Univ.Technol. 15, 824-829.

Yi, H., et al., 2012. An overview of utilization of steel slag. Proc. Environ. Sci. 16, 791-801.

$\mathrm{Yu}, \mathrm{S}$., et al., 2012. Evaluation of chromium bioaccessibility in chromite ore processing residue using in vitro gastrointestinal method. J. Hazard. Mater. 209-210, 250-255.

Zhang, H. Hong, X., 2011. An overview for the utilization of wastes from stainless steel industries. Resour. Conserv. Recy. 55, 745-754. 
Zhang, H., et al., 2014. Pressure oxidative leaching of Indian chromite ore in concentrated $\mathrm{NaOH}$ solution. Hydrometallurgy 142, 47-55.

Zhang, T., et al., 2013. Effectiveness of novel and traditional methods to incorporate industrial wastes in cementitious materials-An overview. Resour. Conserv. Recy. 74, 134-143.

Zhang, Y., et al., 2010. Effect of mechanical activation on alkali leaching of chromite ore. Trans. Nonferros Met. Soc. China. 20, 888-891.

Zhao, Q., et al., 2014. Sulfuric acid leaching of south African chromite. Part I: Study on leaching behavior. Int. J. Miner. Process. 130, 95-101.

Zydorczak, B., et al., 2012. Dissolution of $\mathrm{Cr}_{2} \mathrm{O}_{3}(\mathrm{~s})$ and the behavior of chromium in concentrated $\mathrm{NaOH}$ solutions, I\&EC research 51, 16537-16543. 


\section{List of Figures}

Fig. 1. SEM images of raw material: (a) small oxide (pt 1: spinel in $\mathrm{Cr}$ ) in the silicate matrix (pt 2), (b) FeCr alloy (point $\mathrm{x}$ )

Fig. 2. E-pH diagram at $25^{\circ} \mathrm{C}, 1 \mathrm{~atm},\{$ Metal $\}=0.1 \mathrm{M}$ : (a) $\mathrm{Cr}-\mathrm{H}_{2} \mathrm{O}$ system, (b) $\mathrm{Cr}-\mathrm{Ca}-\mathrm{H}_{2} \mathrm{O}$ system, (c) $\mathrm{Cr}-$ $\mathrm{Mg}-\mathrm{H}_{2} \mathrm{O}$ system, (d) $\mathrm{Cr}-\mathrm{Fe}-\mathrm{H}_{2} \mathrm{O}$ system.

Fig. 3. 2D contour plot of $\mathrm{Cr}$ leaching on temperature and milling time (MA).

Fig 4. Suggested process flow sheet for recycling of $\mathrm{Cr}$ containing slag. 

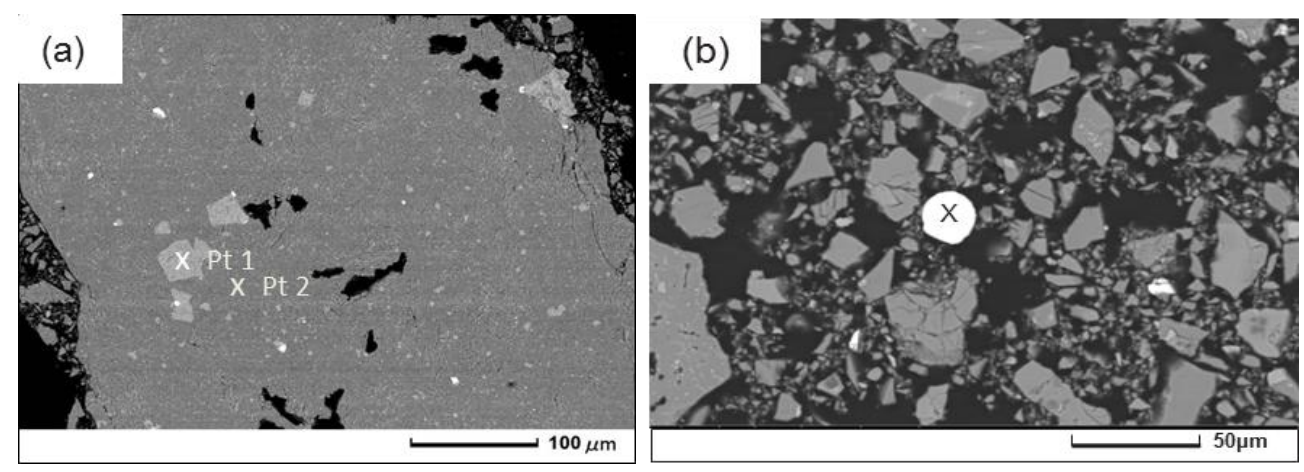

Fig. 1. SEM images of raw material: (a) small oxide (pt 1: spinel in $\mathrm{Cr}$ ) in the silicate matrix (pt 2), (b) FeCr alloy (point $\mathrm{x}$ ) 

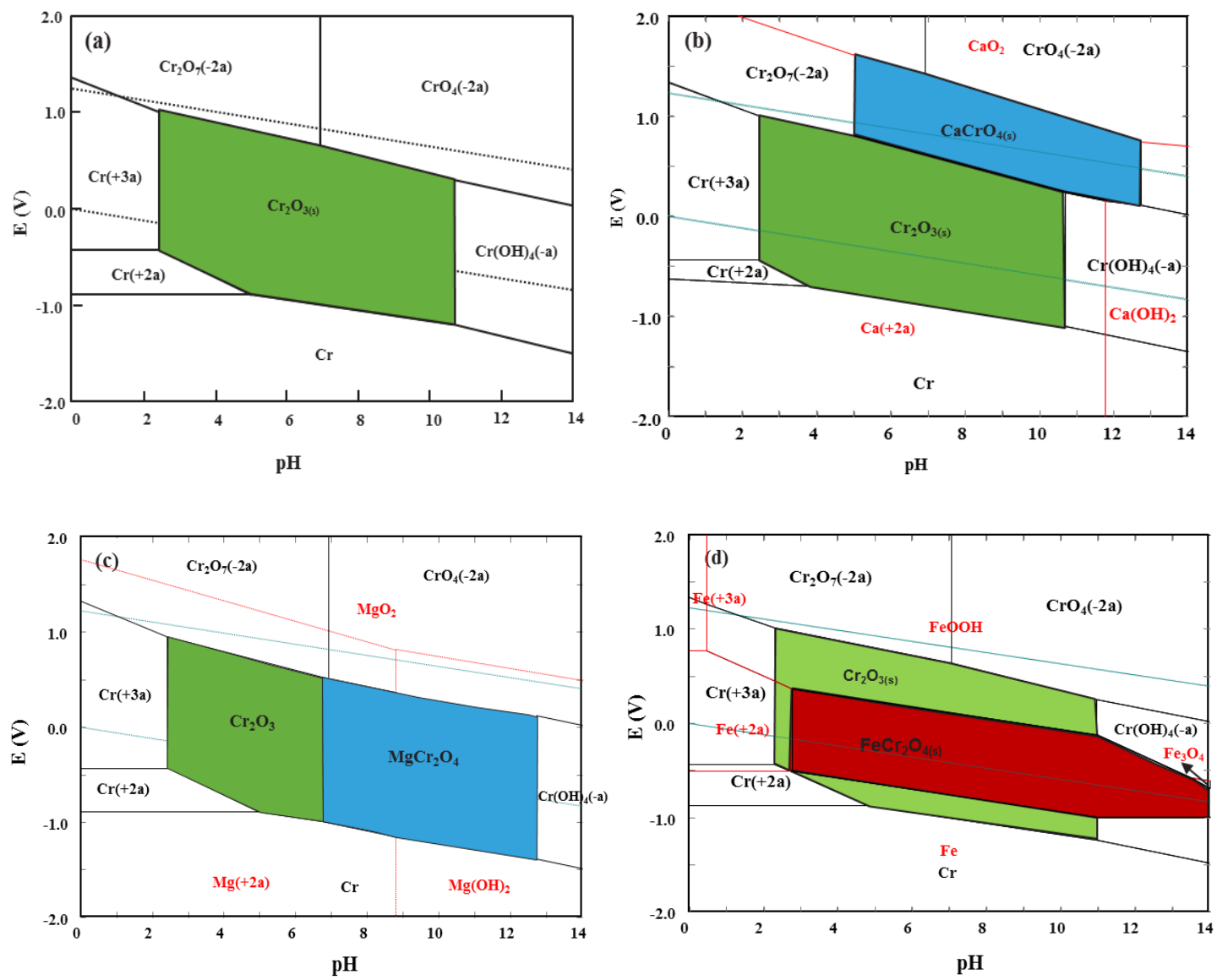

Fig. 2. E-pH diagram at $25^{\circ} \mathrm{C}$, 1 atm, $\{$ Metal $\}=0.1 \mathrm{M}$ : (a) $\mathrm{Cr}-\mathrm{H}_{2} \mathrm{O}$ system, (b) $\mathrm{Cr}-\mathrm{Ca}-\mathrm{H}_{2} \mathrm{O}$ system, (c) $\mathrm{Cr}-\mathrm{Mg}-\mathrm{H}_{2} \mathrm{O}$ system, (d) $\mathrm{Cr}-\mathrm{Fe}-\mathrm{H}_{2} \mathrm{O}$ system. 


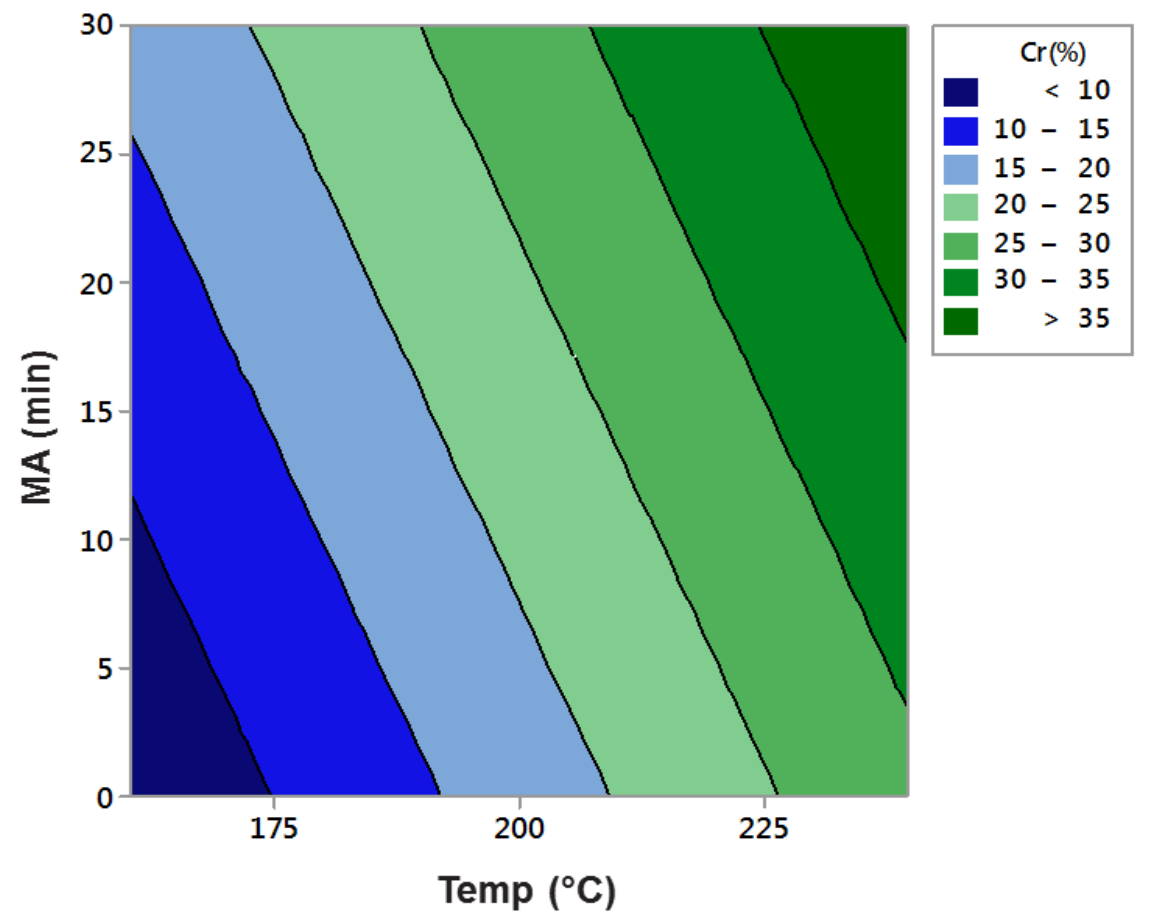

Fig. 3. 2D contour plot of $\mathrm{Cr}$ leaching on temperature and milling time (MA). 


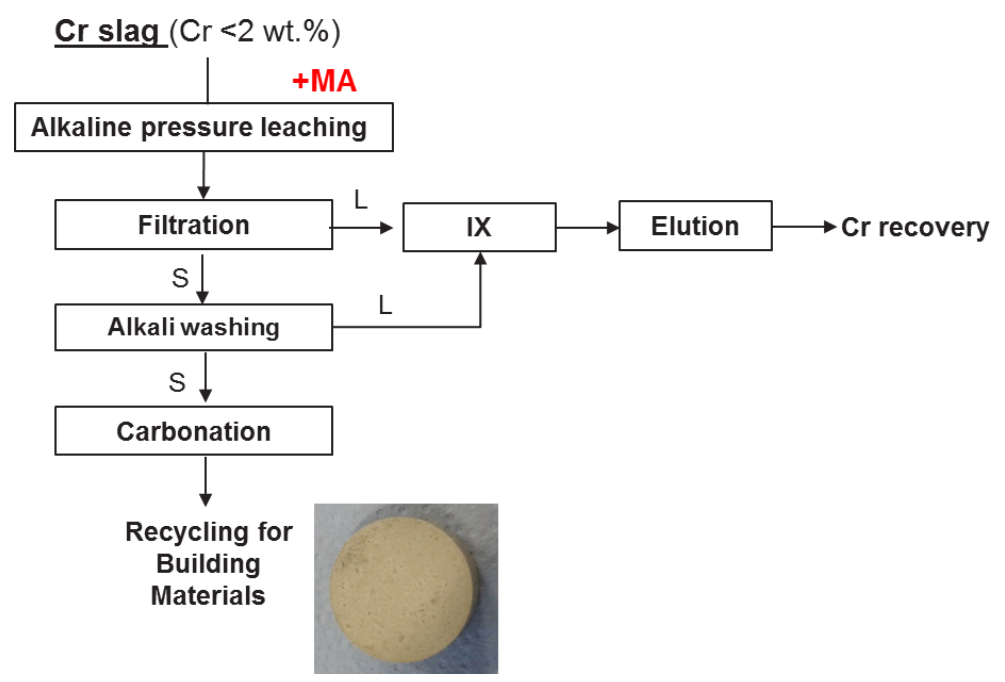

Fig 4. Suggested process flow sheet for recycling of Cr containing slag. 


\section{List of Tables}

Table 1. Design arrangements and $\mathrm{Cr}$ leaching (\%) result (L/S ratio 10)

Table 2. Leaching result of the one-stage leaching test (EN 12357-2) performed on three solid samples obtained after specific washing steps or carbonation (unit: $\mathrm{mg} / \mathrm{kg} \mathrm{dm} \mathrm{slag}$ ) 
Table 1. Design arrangements and $\mathrm{Cr}$ leaching (\%) result (L/S ratio 10)

\begin{tabular}{llllcc}
\hline Run & $\operatorname{Temp}^{\circ}(\mathrm{C})$ & Time $(\mathrm{hr})$ & $\mathrm{NaOH}(\mathrm{M})$ & $\mathrm{MA}(\mathrm{min})$ & $\mathrm{Cr}$ leaching (\%) \\
\hline 1 & 160 & 6 & 1.0 & 0 & 6.9 \\
2 & 240 & 3 & 1.0 & 0 & 23.8 \\
3 & 160 & 3 & 0.5 & 0 & 2.0 \\
4 & 240 & 6 & 1.0 & 30 & 46.0 \\
5 & 160 & 6 & 0.5 & 30 & 12.6 \\
6 & 160 & 3 & 1.0 & 30 & 11.5 \\
7 & 240 & 3 & 0.5 & 30 & 30.0 \\
8 & 200 & 4.5 & 0.75 & 15 & 33.2 \\
9 & 200 & 4.5 & 0.75 & 15 & 35.4 \\
10 & 240 & 6 & 0.5 & 0 & 24.9 \\
\hline
\end{tabular}

Table 2. Leaching result of the one-stage leaching test (EN 12357-2) performed on three solid samples obtained after specific washing steps or carbonation (unit: $\mathrm{mg} / \mathrm{kg} \mathrm{dm}$ slag)

\begin{tabular}{lcccccrccc}
\hline \multicolumn{1}{c}{ Sample } & $\mathrm{Cr}$ & $\mathrm{Fe}$ & $\mathrm{Mn}$ & $\mathrm{Ca}$ & $\mathrm{Mg}$ & \multicolumn{1}{c}{$\mathrm{Si}$} & \multicolumn{1}{c}{$\mathrm{Al}$} & $\mathrm{Ti}$ & $\mathrm{V}$ \\
\hline No. 1 (ultrasonic $+\mathrm{H}_{2} \mathrm{O}$ ) & 1.7 & $<\mathrm{DL}$ & $<\mathrm{DL}$ & 951 & 4.9 & 675 & 0.4 & $<\mathrm{DL}$ & $\mathrm{ND}$ \\
No. 2 (NaOH washing) & 0.8 & $<\mathrm{DL}$ & $<\mathrm{DL}$ & 934 & 0.3 & 58 & 0.3 & $<\mathrm{DL}$ & $\mathrm{ND}$ \\
Carbonation of No. 2 & 0.4 & $<\mathrm{DL}$ & $<\mathrm{DL}$ & 158 & 22.4 & 345 & 0.6 & $<\mathrm{DL}$ & 0.3 \\
\hline
\end{tabular}

DL: Below detection limit

ND: Not determined 